\title{
CFD Study on Wall/Nanoparticle Interaction in Nanofluids Convective Heat Transfer
}

\author{
Mohammad Reza Tarybakhsh, ${ }^{1}$ Ali Akbar Lotfi Neyestanak, ${ }^{2}$ and Hamed Tarybakhsh ${ }^{3}$ \\ ${ }^{1}$ Iranian Academic Center for Education, Culture and Research, Branch of Science \& Technology University (JDEVS), \\ Tehran 1981983889, Iran \\ ${ }^{2}$ Department of Mechanical Engineering, Islamic Azad University, Shahre-Rey Branch, Tehran 144-18155, Iran \\ ${ }^{3}$ Department of Chemical Engineering, Islamic Azad University, Center Tehran Branch, Tehran, Iran \\ Correspondence should be addressed to Ali Akbar Lotfi Neyestanak; aaklotfi@yahoo.com
}

Received 20 May 2013; Revised 31 July 2013; Accepted 24 September 2013

Academic Editor: Alessandro Massaro

Copyright (C) 2013 Mohammad Reza Tarybakhsh et al. This is an open access article distributed under the Creative Commons Attribution License, which permits unrestricted use, distribution, and reproduction in any medium, provided the original work is properly cited.

\begin{abstract}
The Brownian motion of the nanoparticles in nanofluid is one of the potential contributors to enhance effective thermal conductivity and the mechanisms that might contribute to this enhancement are the subject of considerable discussion and debate. In this paper, the mixing effect of the base fluid in the immediate vicinity of the nanoparticles caused by the Brownian motion was analyzed, modeled, and compared with existing experimental data available in the literature. CFD was developed to study the effect of wall/nanoparticle interaction on forced convective heat transfer in a tube under constant wall temperature condition. The results showed that the motion of the particle near the wall which can decrease boundary layer and the hydrodynamics effects associated with the Brownian motion have a significant effect on the convection heat transfer of nanofluid.
\end{abstract}

\section{Introduction}

Fluid heating and cooling play significant roles in a lot of industrial processes such as refinery, petrochemical, power stations, and electronics [1]. Heat transfer in traditional fluids such as water, ethyleneglycol, and oil inherently has low thermal conductivity compared with that in the metals and metal oxides. Therefore, fluids with suspended solid particles are expected to have better heat transfer properties. But, for the particles with millimeter and micron size, there are some problems like sedimentation, clogging, and pressure drop. Choi employed the particles in nanometer dimensions as a suspended solution [2]. An increasing number of experimental investigations have demonstrated that nanofluids can dramatically increase the effective thermal properties of the base fluid [3-12]. Abu-Nada [13] investigated the effects of variable viscosity and thermal conductivity of a nanofluid $\left(\mathrm{Al}_{2} \mathrm{O}_{3}\right.$-water $)$ on the natural convective heat transfer. Sharma et al. [14] experimentally studied the convective heat transfer coefficient and pressure drop in the transient region for $\mathrm{Al}_{2} \mathrm{O}_{3}$-water nanofluid under a constant heat flux.
They found that convective heat transfer increases by adding $\mathrm{Al}_{2} \mathrm{O}_{3}$ nanoparticles in water. Moraveji et al. [15] simulated water- $\mathrm{Al}_{2} \mathrm{O}_{3}$ nanofluid through a tube under a constant heat flux. They found that the heat transfer coefficient rises by increasing the nanoparticle concentration and Reynolds number. Furthermore, the heat transfer coefficient increases by particle diameter reduction.

Because of these suitable properties and the excellent stability of these fluids, nanofluids present a promising alternative to traditional heat transfer fluids in a wide range of applications. However, the precise mechanisms that contribute to the observed enhancement are not currently well understood and no widely accepted explanations have been identified. As a result, in order to fully understand the mechanisms that govern the enhancement of these nanofluids and optimize the thermophysical properties, the mixing effect of the base fluid in the immediate vicinity of the nanoparticles caused by the Brownian motion of the nanoparticles was analyzed, modeled, and compared with existing experimental data available in the literature. Due to the lack of experimental tools required to isolate the effect of each mechanisms, many 


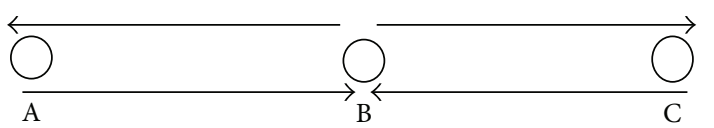

FIGURE 1: Trajectory of nanoparticle.

investigations have focused only on the Brownian motion effects of the nanoparticles, using either numerical simulation or experimental techniques [16-22]. Considering some of the molecular simulations, it was concluded that Brownian motion of nanoparticles has no impact on the effective thermal conductivity of the nanofluids [18], while the experimental study of nanofluids diffusion provides some evidence for the contribution of the Brownian motion effects, along with other factors [18-20]. In order to have better understanding of the governing phenomena and to determine the contribution of Brownian motion, a numerical simulation was conducted to determine the validity of the previously stated conclusions [23, 24].

In this research, the convective heat transfer near the wall region of the tube flow containing water and $\mathrm{Al}_{2} \mathrm{O}_{3}$ nanofluid under a constant temperature was simulated using the Computational Fluid Dynamics (CFD) tools. $\mathrm{Al}_{2} \mathrm{O}_{3}$ nanoparticle with average diameters of $27 \mathrm{~nm}$ was used. The effects of the nanoparticle Brownian motion on the convective heat transfer coefficient were investigated near the wall.

\section{The Simulation of Brownian Motion Effect on the Effective Thermal Convection}

Visual observations of Brownian motion indicate that each nanoparticle can be modeled as having a local periodic motion within the suspension, as shown in Figure 1. As illustrated, points $\mathrm{A}$ and $\mathrm{C}$ can be used to represent the farthest points of local periodic motion, and point $\mathrm{B}$ is the location at which the local periodic motion has the highest velocity. Based upon this diagram, the velocity and the range of influence can be determined from the following expressions:

$$
\begin{gathered}
m \frac{d^{2} y}{d t^{2}}+b y=0 \\
x(t)=y_{0} \cos \omega t+\frac{v_{0}}{\omega} \sin \omega t,
\end{gathered}
$$

where $m$ is mass, $x$ displacement, $t$ time, $b$ constant, $x$ angular velocity, $m_{0}$ viscosity, and $x_{0}$ the initial location. UFD code in the model includes Brownian motion.

2.1. CFD Model. The influence range for this local periodic motion model can be calculated by solving the governing equations of the convection caused by the motion of $\mathrm{Al}_{2} \mathrm{O}_{3}$ nanoparticles in three dimensions. Figure 2 shows the geometry of CFD model. The Brownian motion of nanoparticle in nanofluid flow with a velocity of $1 \mathrm{~m} / \mathrm{s}$ and a temperature of $24^{\circ} \mathrm{C}$ in a tube was modeled by CFD method and the result was discussed. Water flow in a small tube (diameter $=0.2$ micron, length $=1$ micro) with nanoparticle motion near the wall was studied. The particle has a constant velocity of $1 \mathrm{~m} / \mathrm{s}$ in $x$-direction and a periodic motion in $y$-direction.

The surface of nanoparticles was assumed to be adiabatic, and wall 2 was supposed to be a heated surface, with a constant temperature of $24.1^{\circ} \mathrm{C}$, as shown in Figure 2. For the purpose of parametric study, initial temperature of water flow,

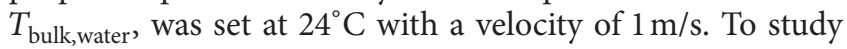
the convective heat transfer enhancement effect, temperature gradient was assumed between fluid and wall temperatures; in addition, particle motion effects were modeled near the wall.

To model fluids and heat transfer, the two-dimensional computational grids consisting unstructured cells were used separately in some cases. It has been proven that the unstructured cell technology is a significant improvement in terms of meshing flexibility and simulation time to perform a complete simulation. The mesh size surrounding the particle is too fine to predict the variation of pressure, velocity, and temperature with high accuracy, but it has normal size near the walls to increase the calculation speed (Figure 3).

In Figure 3 the mesh is generated with 1.25 million mesh elements. The nanoparticle has a diameter of $26 \mathrm{~nm}$ including the possible adsorption layer [25] which is the actual regime for mutual interaction between liquid molecules and nanoparticle surface. The flow domain volume is $200 \times$ $1000 \mathrm{~nm}$. For this model, the transient state was modeled. The actual time needed to compute is approximately $24 \mathrm{~h}$ in order to achieve a convergent steady-state solution. A refined grid analysis may have resulted in a greater mesh refinement in the region of nanoparticles, but the current grid appeared to have enough accuracy for this single nanoparticle case study.

Transient CFD code was prepared based on the SIMPLE algorithm and second order upwind method allows calculating with Cartesian and cylindrical coordinates. Modeling of the Brownian motion via CFD requires geometry specification through identifying the computational grid, numerical solution strategy, and specification conditions.

The base fluid phase considered here was assumed to be Newtonian with laminar flow and to have constant physical properties except heat capacity and conductivity coefficient. Nanoparticle periodic motion model and the governing equations (continuity, momentum, and energy) for the convection caused by nanoparticles motion in two-dimensional form can be determined as shown below:

$$
\begin{gathered}
\frac{\partial \rho}{\partial \tau}+\frac{\partial \rho u}{\partial x}+\frac{\partial \rho v}{\partial y}=0 \\
\rho\left(\frac{\partial u}{\partial \tau}+u \frac{\partial u}{\partial x}+v \frac{\partial u}{\partial y}\right)=F_{x}-\frac{\partial p}{\partial x}+\mu\left(\frac{\partial^{2} u}{\partial x^{2}}+\frac{\partial^{2} u}{\partial y^{2}}\right) \\
\rho\left(\frac{\partial u}{\partial \tau}+u \frac{\partial u}{\partial x}+v \frac{\partial u}{\partial y}\right)=F_{x}-\frac{\partial p}{\partial x}+\mu\left(\frac{\partial^{2} u}{\partial x^{2}}+\frac{\partial^{2} u}{\partial y^{2}}\right) \\
\rho C_{p} \frac{d T}{d \tau}=\frac{\partial}{\partial x}\left(k \frac{\partial T}{\partial x}\right)+\frac{\partial}{\partial y}\left(k \frac{\partial T}{\partial y}\right)+\alpha_{v} T \frac{d P}{d \tau}+\mu \Phi
\end{gathered}
$$

where $\rho$ is the density, $u, v, w, F_{x}$, and $F_{y}$ are the velocity components and external forces in the $x$-, $y$-directions, respectively, $P$ is the static pressure, $C_{p}$ is the specific heat 


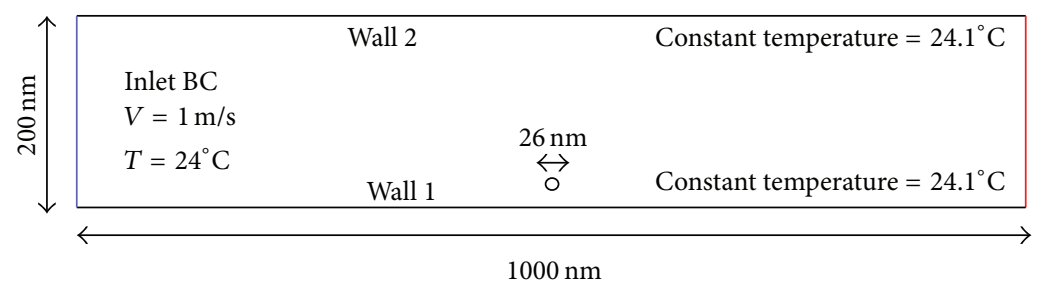

FIGURE 2: Geometry and boundary condition of system.

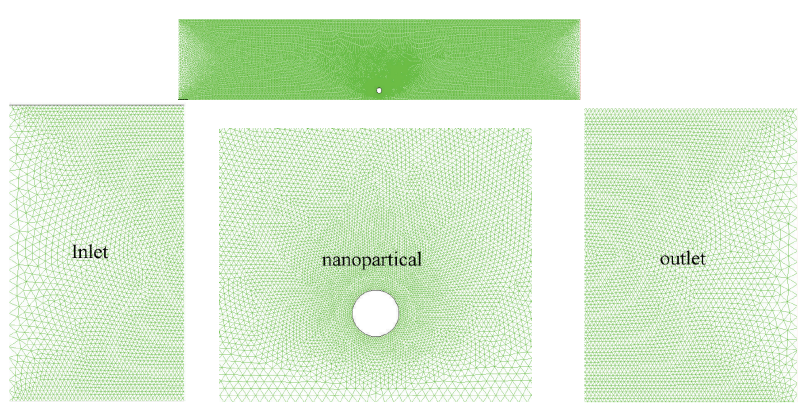

Figure 3: Mesh model of base case.

capacity, $T$ is the temperature, $k$ is the thermal conductivity, $\alpha_{v}$ is the expansion coefficient, $\mu$ is the viscosity, and $\Phi$ is the diffusion matrix. The grid model was generated by Gambit and solved by Ansys Fluent 6.3 and Brownian motion was added to the fluent model by UFD file. The transient state was modeled using a time step of $d t=1 e-7 \mathrm{~s}$ and a total time of $0.001 \mathrm{~s}$. To study the Brownian motion effect, initially the water fluid flow in a tube containing no nanoparticle and that in the case of single nanoparticle were studied besides the isothermal, pressure, and velocity fields. Finally, the effect of multiple nanoparticles was studied, too.

\section{Result and Discussion}

3.1. Case 1: Laminar Fluid Flow without Nanoparticle. In the first case, To show the effect of nanoparticle interaction with wall in fluid flow, first the model was performing without nanoparticle and then the nanopartical interaction effect was studied. The boundary condition was defined as mentioned above. Figure 4 illustrates the temperature gradient expected in the flow tube. According to the temperature counter the parameters gradient is very high in the entrance zone and not fully developed.

3.2. Case 2: Laminar Fluid Flow with One Nanoparticle. In this case, a nanoparticle was located near wall 2 at the same distance from the inlet and outlet. The particle moves through fluid in $x$-direction $(V=1 \mathrm{~m} / \mathrm{s})$ and has very small periodic motion in $y$-direction. The boundary and initial conditions were temperature (walls 1 and $2: 24.1^{\circ} \mathrm{C}$, inlet nanofluid temp.: $24^{\circ} \mathrm{C}$ ), velocity (inlet nanofluid: $1 \mathrm{~m} / \mathrm{s}$, initial nanoparticle: $001 \mathrm{~m} / \mathrm{s}$ ), and $d t=1 e-7$. Figure 5 shows the typical simulated velocity, temperature, and pressure

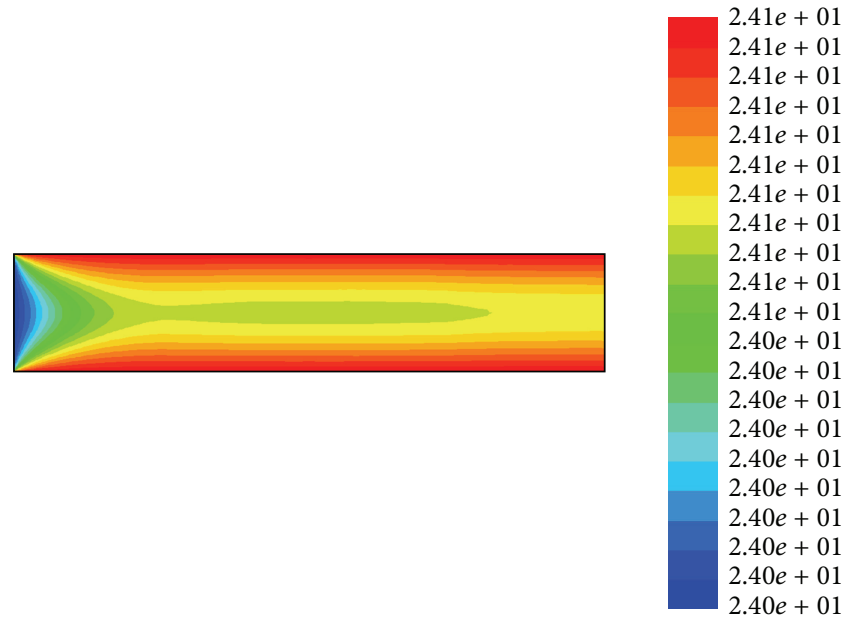

FIGURE 4: Case 1 , temperature gradient $($ time $=0.001 \mathrm{~S})$.

field around a nanoparticle after the first stage of modeling. As indicated, mixing flow has the enhancement effect of Brownian motion in nanofluid on convective heat transfer in comparison with the results of Case 1 . As the nanoparticle surface was treated as adiabatic, there is an isothermal curvature because of the microconvection induced by Brownian motion of nanoparticle.

The pressure field at the top of Figure 5 shows that the pressure in front of the nanoparticle increases very quickly and it is larger than that behind the nanoparticle.

Figure 6 illustrates the heat transfer coefficient in walls 1 and 2 versus tube length. Figure 6(a) shows that heat transfer coefficient changes through the whole length of the tube and Figure 6(b) indicates changes in the range of nanoparticles.

Increase in convective heat transfer coefficient near the wall 2 shows the effect of nanoparticle Brownian motion. This motion causes reduction in heat and fluid boundary layer near the wall. Furthermore, the microconvection of vibration motion leads to increasing the convective heat transfer coefficient, as obviously seen in the figure.

3.3. Case 3: Laminar Fluid Flow with Two Adjacent Nanoparticles and the Effect of Brownian Motion. In this case, the effect of two adjacent nanoparticles, instead of one nanoparticle was studied. The distance between two particles is $30 \mathrm{~nm}$. The boundary and initial conditions are the same as Case 1. 


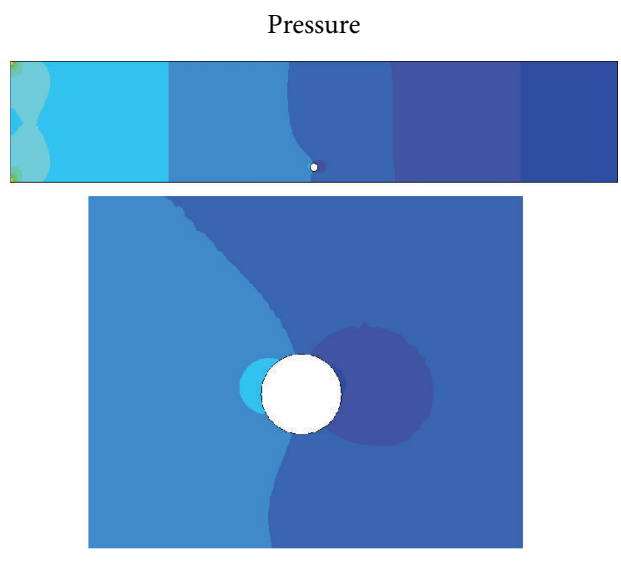

(a)

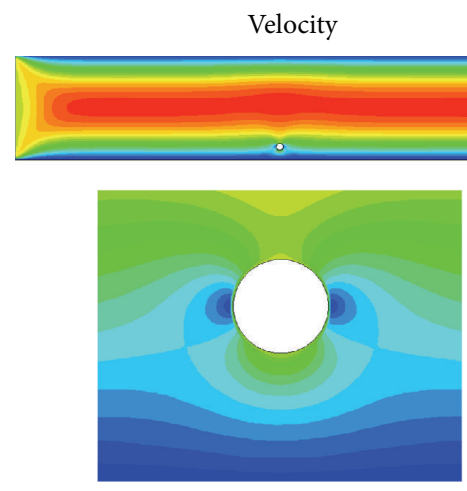

(c)

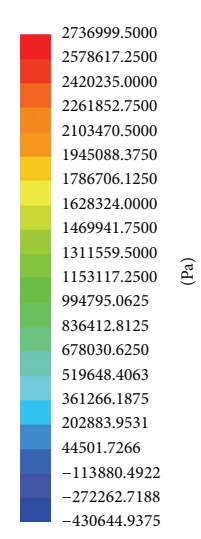

$-430644.9375$

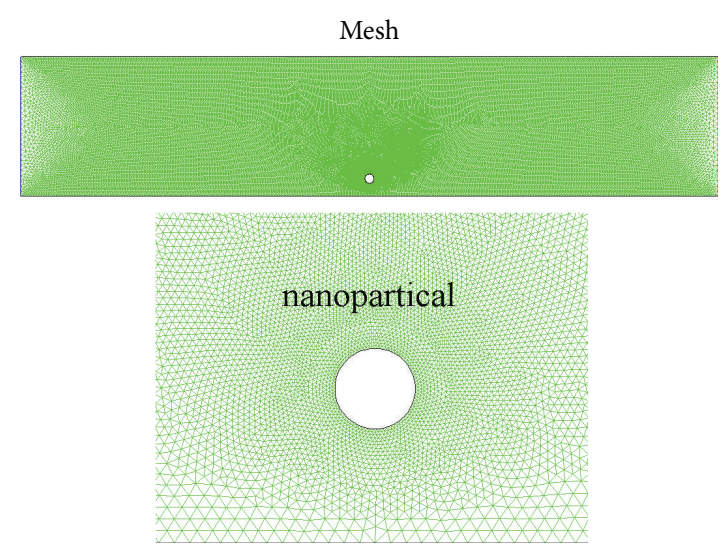

(b)

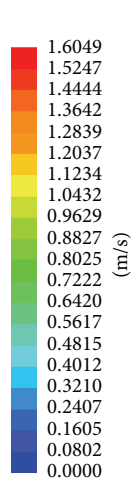

1.6049
1.5247
1.4444
1.3642
1.2839
1.2037
1.1234
1.0432
0.9629
0.8827 क्
0.8025
0.7222
0.6420
0.5617
0.4815
0.4012
0.3210
0.2407
0.1605
0.0802
0.0000

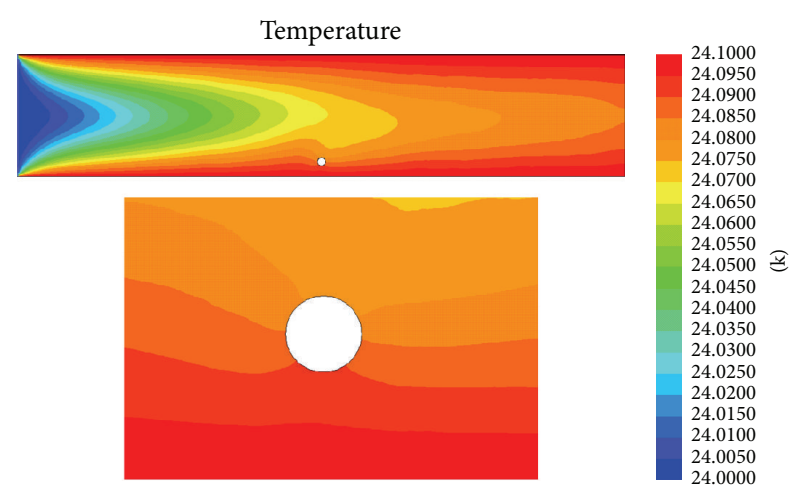

(d)

Figure 5: Case 2, velocity, temperature and pressure gradient, and mesh model (time $=0.001 \mathrm{~S}$ ).

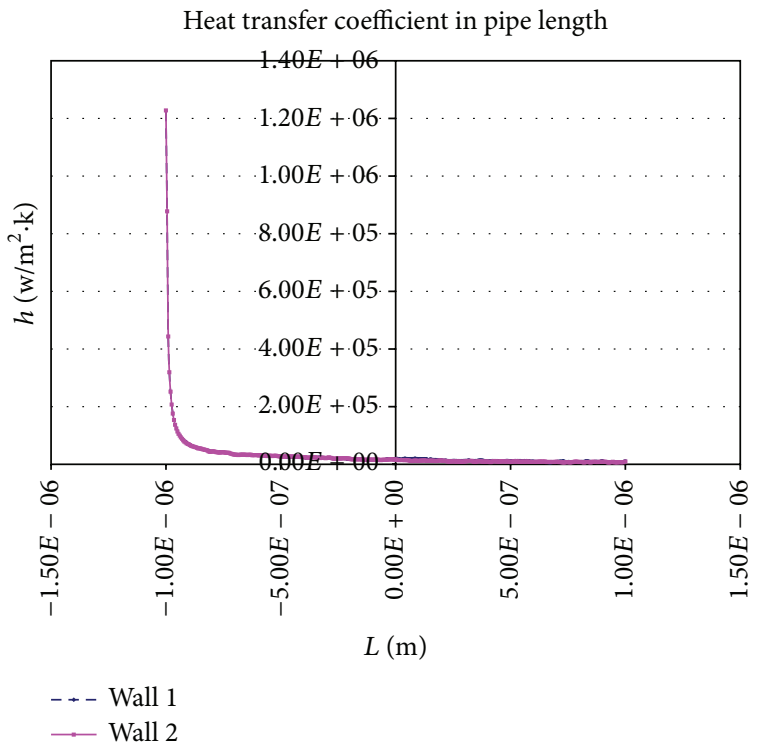

(a)

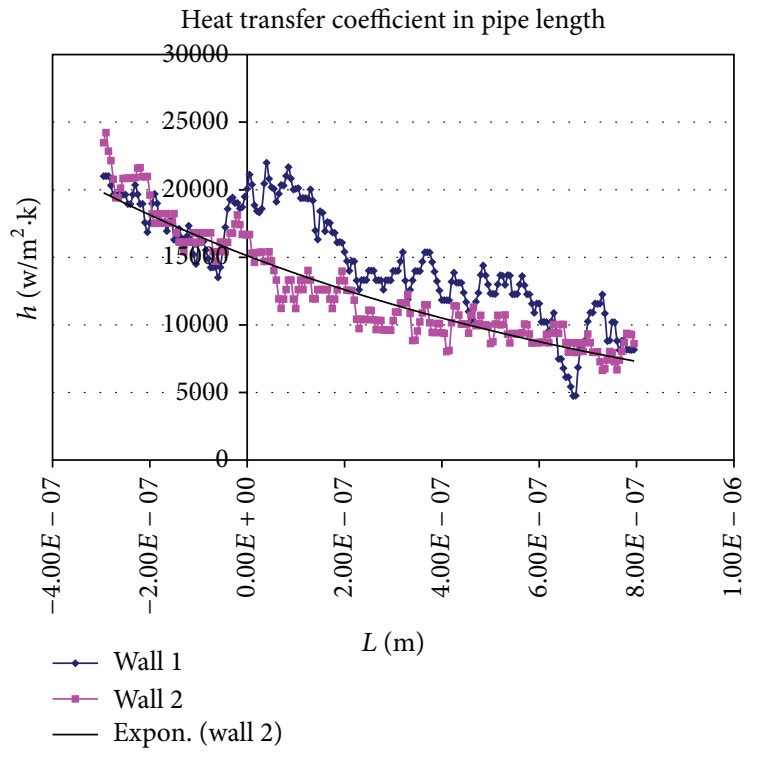

(b)

FIGURE 6: Case 2, convective heat transfer coefficient on walls 1 and 2. 


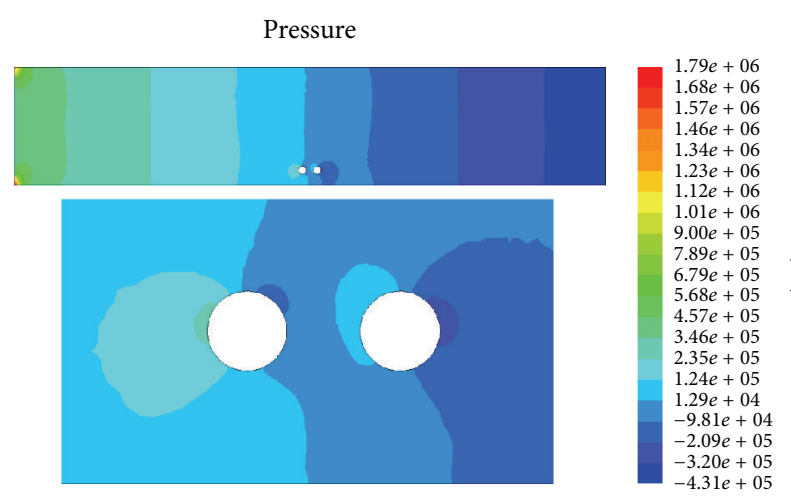

(a)

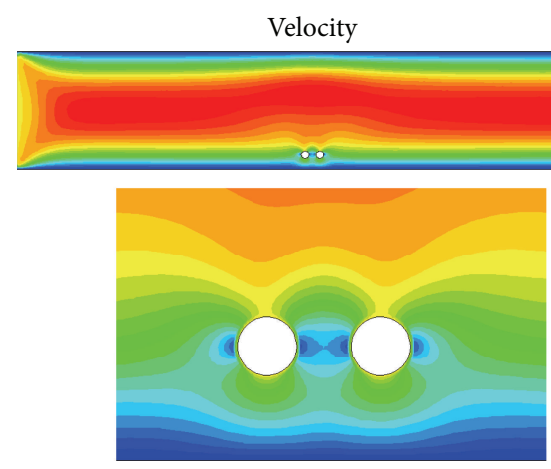

(c)

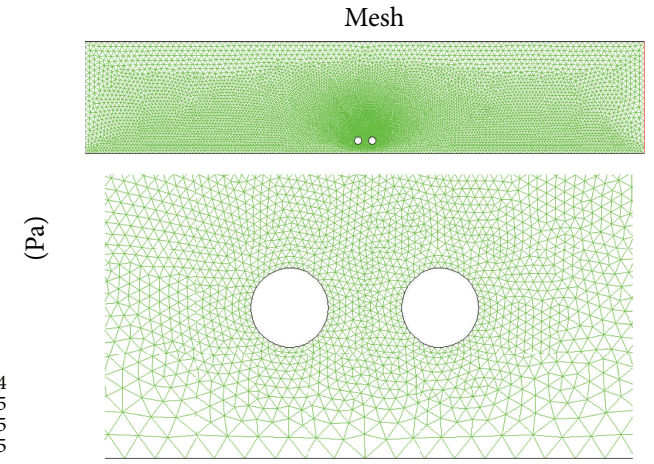

(b)

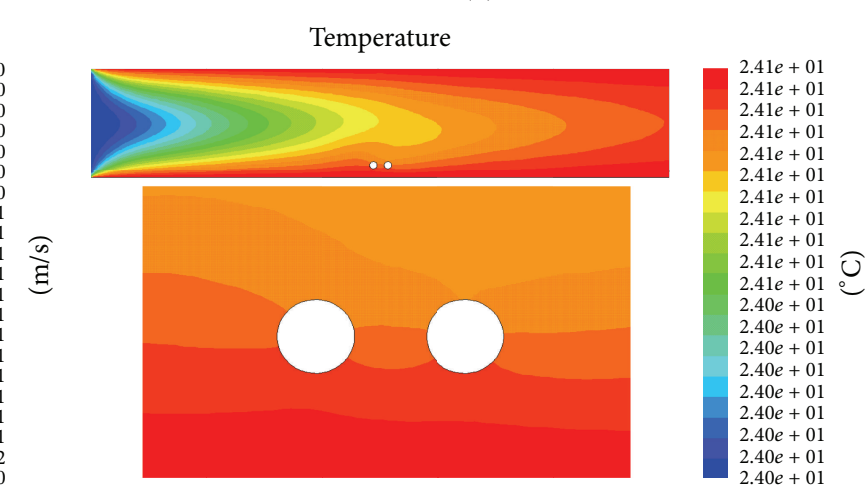

(d)

FIGURE 7: Case 3, velocity, temperature, pressure gradient, and mesh model (time $=0.001 \mathrm{~S}$ ).

Figure 7 illustrates the velocity, temperature, and pressure gradient.

Compared with the results and heat transfer rate related to the model of Figures 5 and 7, it is clear that the second nanoparticle causes increase in heat transfer from the wall to the fluid which is shown by the counters of these two figures. This improvement is due to the mutual effects of the nanoparticles. Therefore, increase in nanoparticle concentration because of microconvection enhancement leads to higher heat transfer coefficient in the fluid.

The model of two adjacent nanoparticles clarifies how the induced microconvection influences the convective heat transfer coefficient of base fluid. Also, the modeling of two adjacent nanoparticles clarifies how the induced microconvection effects the heat transfer capability.

Figure 8 illustrates the heat transfer coefficient of walls 1 and 2. As seen in the figure, blue parts which indicate convective heat transfer coefficient near wall 2 show larger growth rate compared with that in Figure 6 in the case of one nanoparticle. So, it can imply the effect of more particles in the base fluid that researchers have mentioned [23, 24].

When two nanoparticles are close to each other, the influence on the area will be more than twice due to the hydrodynamic interaction. This, in turn, increases the heat transfer capacity of the nanofluid at macroscale.

\section{Conclusions}

This paper discussed the Brownian motion effect as one of the main factors for enhancing forced convective heat transfer coefficient of nanofluids. The corresponding temperature, pressure, and velocity fields were simulated using CFD model and a finite-difference algorithm. The simulations for single and adjacent nanoparticles were discussed in detail. The results clearly indicated that microconvection/mixing induced by the Brownian motion of nanoparticles could significantly affect the macroconvective heat transfer capability of the nanofluids. This information is especially interesting when accompanied with other works on the variation of the viscosity of nanofluids, due to the Brownian motion and hydrodynamic interaction between nanoparticles [26-30]. The results indicated the effect of the microconvection in these types of suspensions and demonstrate that Brownian motion is one of the key factors in relation to the observed high effective thermal convection of nanofluids. Also, results showed that the temperature of two adjacent nanoparticles is higher than that of one nanoparticle, which means that the hydrodynamic interaction between the nanoparticles dramatically enhances the thermal transport capability and the nanoparticles, not only in front of, but also behind, the nanoparticles. It is also apparent that two adjacent nanoparticles in close proximity will have a greater influence 


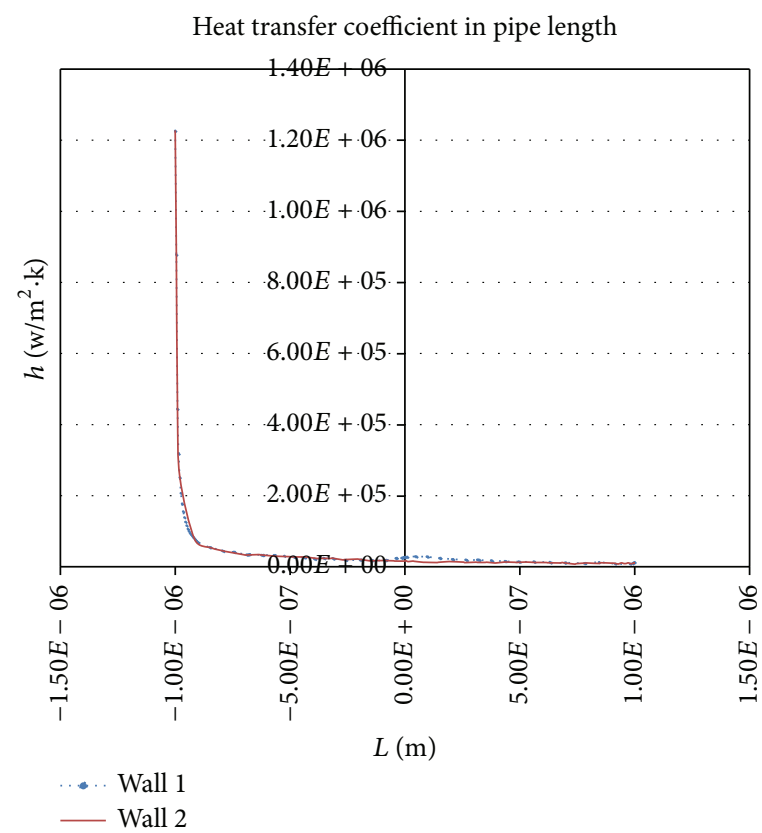

(a)

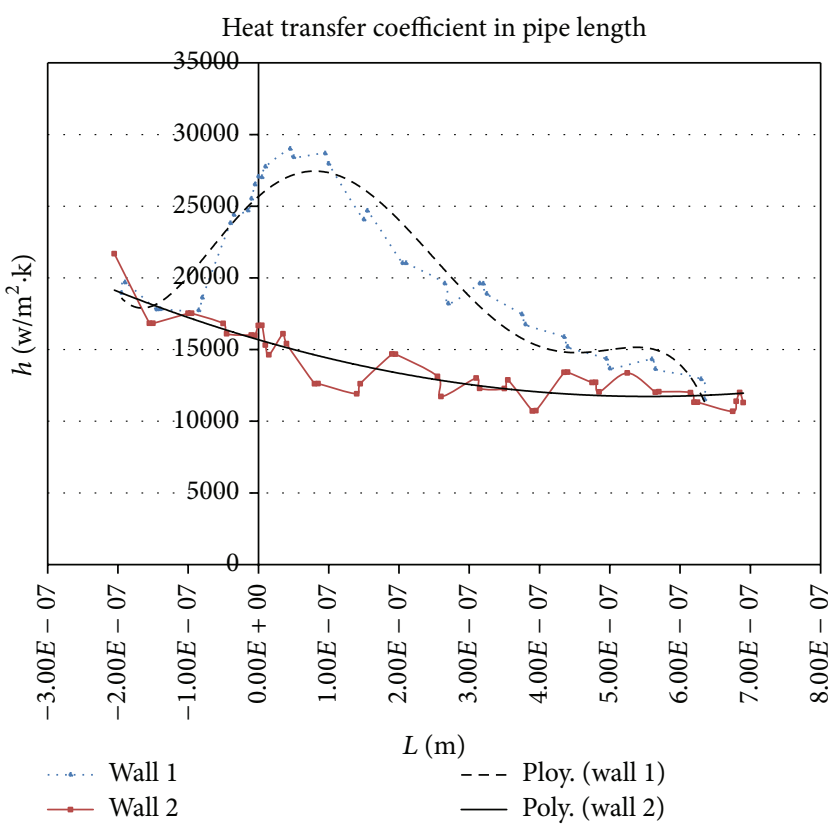

(b)

Figure 8: Case 3, convective heat transfer coefficient on walls 1 and 2.

on the temperature field than two single nanoparticles, far apart from each other, due to the interaction.

\section{Nomenclature}

$\begin{array}{ll}m: & \text { Mass, } \mathrm{kg} \\ x: & \text { Displacement, } \mathrm{m} \\ t: & \text { Time, } \mathrm{s} \\ \omega: & \text { Angular velocity, } \mathrm{m} / \mathrm{s} \\ x_{0}: & \text { Initial location, } \mathrm{m} \\ \rho: & \text { Density, } \mathrm{kg} / \mathrm{m}^{3} \\ u, v, w: & \text { Velocity components, } \mathrm{m} / \mathrm{s} \\ F_{x}, F_{y}: & \text { External forces, } \mathrm{N} \\ P: & \text { Static pressure, } \mathrm{N} / \mathrm{m}^{2} \\ C_{p}: & \text { Specific heat capacity } \\ \alpha_{v}: & \text { Expansion coefficient } \\ M: & \text { Viscosity } \\ \Phi: & \text { Diffusion matrix } \\ T: & \text { Temperature, } \mathrm{k} \\ K: & \text { Thermal conductivity, } \mathrm{W} / \mathrm{m} \cdot \mathrm{k} \\ q: & \text { Heat flux, } \mathrm{W} / \mathrm{m}^{2} .\end{array}$

\section{References}

[1] R. Davarnejad, S. Barati, and M. Kooshki, "CFD simulation of the effect of particle size on the nanofluids convective heat transfer in the developed region in a circular tube," SpringerPlus, vol. 2, no. 1, article 192, 2013.

[2] S. U. S. Choi, "Enhancing thermal conductivity of fluids with nanoparticles," in Developments and Applications of NonNewtonian Flows, D. A. Siginer and H. P. Wang, Eds., The American Society of Mechanical Engineers, New York, NY, USA, 1995.
[3] V. Trisaksri and S. Wongwises, "Critical review of heat transfer characteristics of nanofluids," Renewable and Sustainable Energy Reviews, vol. 11, no. 3, pp. 512-523, 2007.

[4] X.-Q. Wang and A. S. Mujumdar, "Heat transfer characteristics of nanofluids: a review," International Journal of Thermal Sciences, vol. 46, no. 1, pp. 1-19, 2007.

[5] X.-Q. Wang and A. S. Mujumdar, "A review on nanofluids. Part I: theoretical and numerical investigations," Brazilian Journal of Chemical Engineering, vol. 25, no. 4, pp. 613-630, 2008.

[6] Y. Li, J. Zhou, S. Tung, E. Schneider, and S. Xi, "A review on development of nanofluid preparation and characterization," Powder Technology, vol. 196, no. 2, pp. 89-101, 2009.

[7] S. Kakaç and A. Pramuanjaroenkij, "Review of convective heat transfer enhancement with nanofluids," International Journal of Heat and Mass Transfer, vol. 52, no. 13-14, pp. 3187-3196, 2009.

[8] K. V. Wong and O. de Leon, "Applications of nanofluids: current and future," Advances in Mechanical Engineering, vol. 2010, Article ID 519659, 11 pages, 2010.

[9] G. Donzelli, R. Cerbino, and A. Vailati, "Bistable heat transfer in a nanofluid," Physical Review Letters, vol. 102, no. 10, Article ID 104503, 2009.

[10] M. Arruebo, R. Fernández-Pacheco, M. R. Ibarra, and J. Santamaría, "Magnetic nanoparticles for drug delivery," Nano Today, vol. 2, no. 3, pp. 22-32, 2007.

[11] W. Yu, D. M. France, D. Singh, E. V. Timofeeva, D. S. Smith, and J. L. Routbort, "Mechanisms and models of effective thermal conductivities of nanofluids," Journal of Nanoscience and Nanotechnology, vol. 10, no. 8, pp. 4824-4849, 2010.

[12] G. Paul, M. Chopkar, I. Manna, and P. K. Das, "Techniques for measuring the thermal conductivity of nanofluids: a review," Renewable and Sustainable Energy Reviews, vol. 14, no. 7, pp. 1913-1924, 2010.

[13] E. Abu-Nada, "Effects of variable viscosity and thermal conductivity of $\mathrm{Al}_{2} \mathrm{O}_{3}$ : water nanofluid on heat transfer enhancement 
in natural convection," International Journal of Heat and Fluid Flow, vol. 30, no. 4, pp. 679-690, 2009.

[14] K. V. Sharma, L. S. Sundar, and P. K. Sarma, "Estimation of heat transfer coefficient and friction factor in the transition flow with low volume concentration of $\mathrm{Al}_{2} \mathrm{O}_{3}$ nanofluid flowing in a circular tube and with twisted tape insert," International Communications in Heat and Mass Transfer, vol. 36, no. 5, pp. 503-507, 2009.

[15] M. K. Moraveji, M. Darabi, S. M. H. Haddad, and R. Davarnejad, "Modeling of convective heat transfer of a nanofluid in the developing region of tube flow with computational fluid dynamics," International Communications in Heat and Mass Transfer, vol. 38, no. 9, pp. 1291-1295, 2011.

[16] S. K. Gupte, S. G. Advani, and P. Huq, "Role of micro-convection due to non-affine motion of particles in a mono-disperse suspension," International Journal of Heat and Mass Transfer, vol. 38, no. 16, pp. 2945-2958, 1995.

[17] P. Bhattacharya, S. K. Saha, A. Yadav, P. E. Phelan, and R. S. Prasher, "Brownian dynamics simulation to determine the effective thermal conductivity of nanofluids," Journal of Applied Physics, vol. 95, no. 11, pp. 6492-6494, 2004.

[18] W. Evans, J. Fish, and P. Keblinski, "Role of Brownian motion hydrodynamics on nanofluid thermal conductivity," Applied Physics Letters, vol. 88, no. 9, Article ID 093116, 2006.

[19] S. Krishnamurthy, P. Bhattacharya, P. E. Phelan, and R. S. Prasher, "Enhanced mass transport in nanofluids," Nano Letters, vol. 6, no. 3, pp. 419-423, 2006.

[20] T. K. Hong and H. S. Yang, "Study of the enhanced thermal conductivity of Fe nanofluids," Journal of Applied Physics, vol. 97, Article ID 064311, 2005.

[21] K. S. Hong, "Thermal conductivity of Fe nanofluids depending on the cluster size of nanoparticles," Applied Physics Letters, vol. 88, Article ID 031901, 2006.

[22] C. H. Li and G. P. Peterson, "Experimental investigation of temperature and volume fraction variations on the effective thermal conductivity of nanoparticle suspensions (nanofluids)," Journal of Applied Physics, vol. 99, no. 8, Article ID 084314, 2006.

[23] Z. Haddad, E. Abu-Nada, H. F. Oztop, and A. Mataoui, "Natural convection in nanofluids: are the thermophoresis and Brownian motion effects significant in nanofluid heat transfer enhancement?" International Journal of Thermal Sciences, vol. 57, pp. 152-162, 2012.

[24] R. Azizian, E. Doroodchi, and B. Moghtaderi, "Effect of nanoconvection caused by Brownian motion on the enhancement of thermal conductivity in nanofluids," Industrial and Engineering Chemistry Research, vol. 51, no. 4, pp. 1782-1789, 2012.

[25] B. X. Wang, H. Li, and X. F. Peng, "Research on the heat-conduction enhancement for liquid with nano-particle suspension," Journal of Thermal Science, vol. 11, no. 3, pp. 214-219, 2002.

[26] J. F. Brady, R. J. Phillips, J. C. Lester, and G. Bossis, "Dynamic simulation of hydrodynamically interacting suspensions," Journal of Fluid Mechanics, vol. 195, pp. 257-280, 1988.

[27] K. Vondermassen, J. Bongers, A. Mueller, and H. Versmold, "Brownian motion: a tool to determine the pair potential between colloid particles," Langmuir, vol. 10, no. 5, pp. 1351-1353, 1994.

[28] A. J. Banchio, J. Gapinski, A. Patkowski et al., "Many-body hydrodynamic interactions in charge-stabilized suspensions," Physical Review Letters, vol. 96, no. 13, Article ID 138303, 2006.

[29] G. P. Peterson, C. H. Li, J. P. Hartnett, and T. F. Irvine, Advances in Heat Transfer, vol. 39, Pergamon, New York, NY, USA, 2005.
[30] G. K. Batchelor, "Brownian diffusion of particles with hydrodynamic interaction," Journal of Fluid Mechanics, vol. 74, no. 1, pp. $1-29,1976$. 

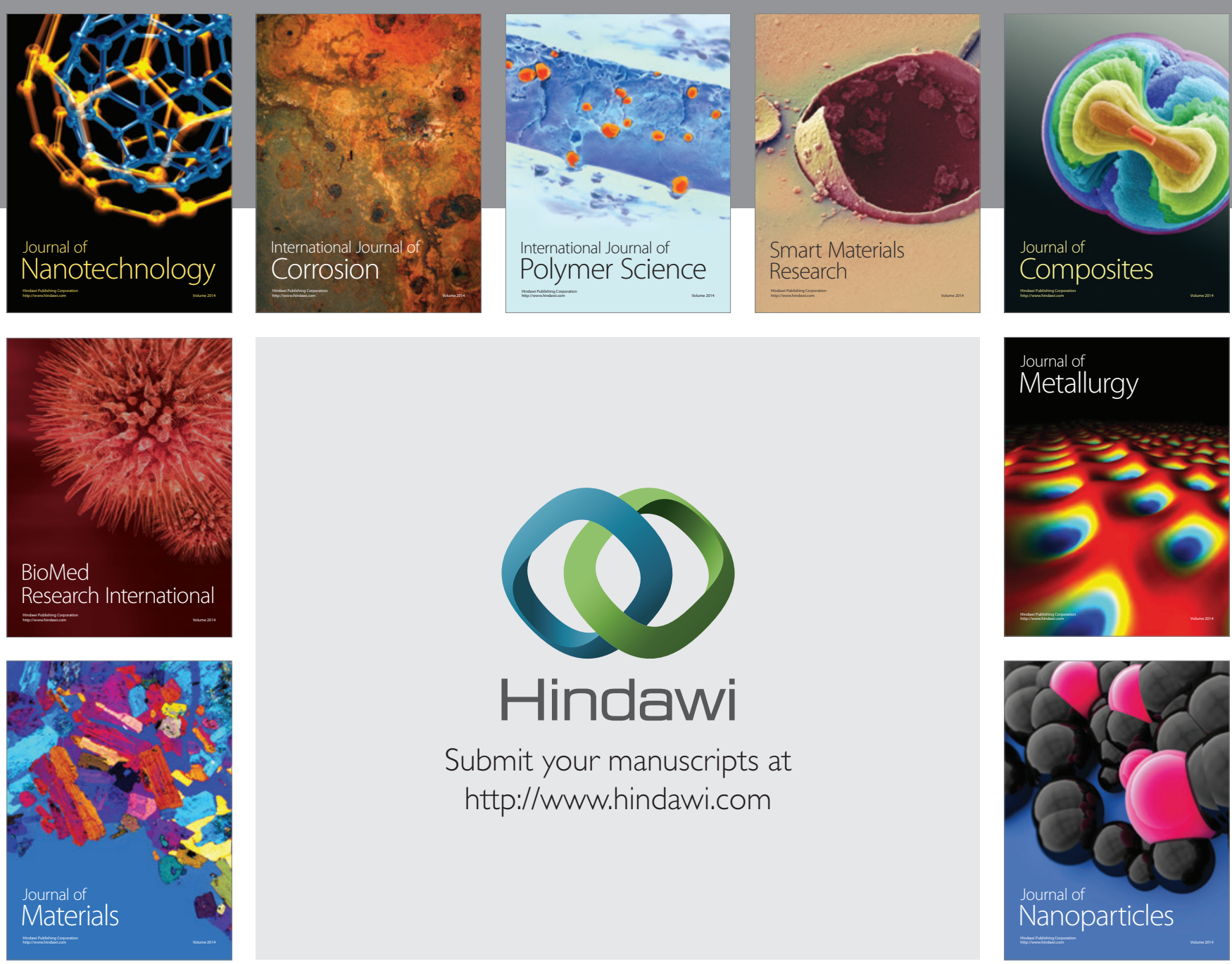

Submit your manuscripts at http://www.hindawi.com
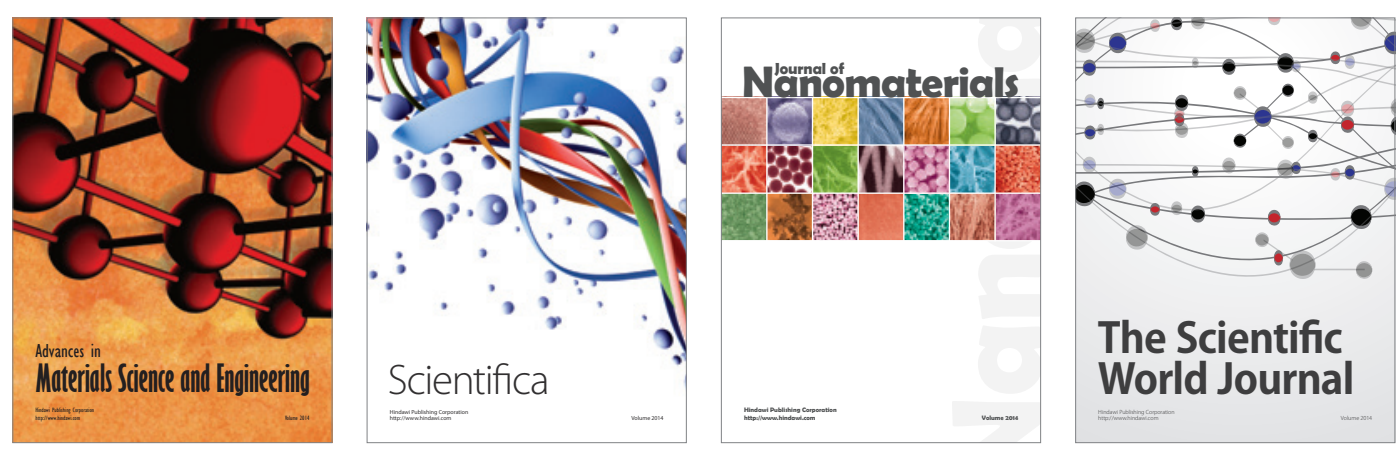

\section{The Scientific World Journal}
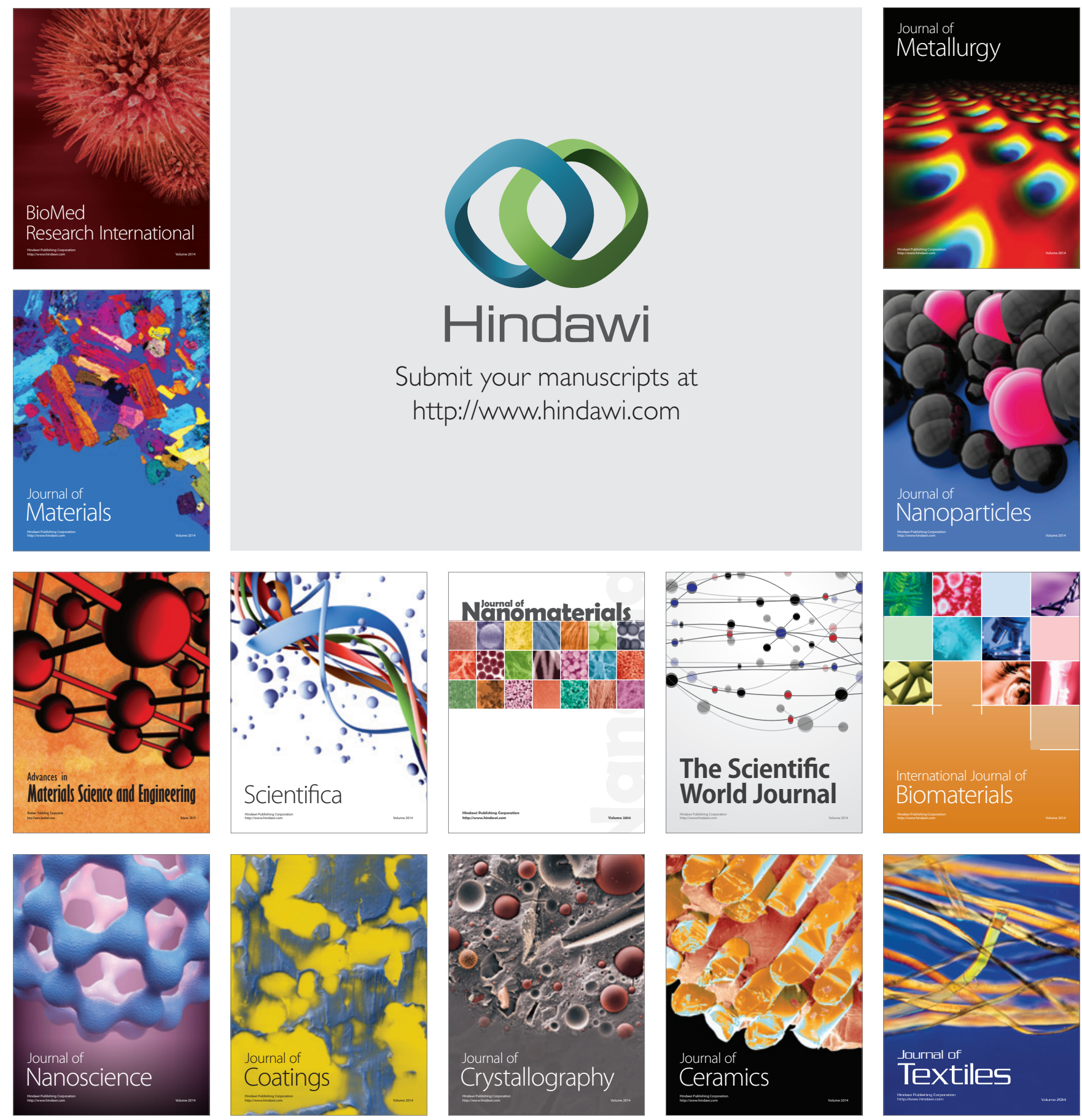